\title{
Causality-Based Policy Learning Frameworks Derived from Russian Power Sector Liberalisation
}

\author{
Marcel Lamoureux* \\ Staffordshire University, Stoke-on-Trent, United Kingdom
}

\begin{abstract}
This paper is an inductive, qualitative case study concerning the development of new policy learning theory derived from Russian power sector liberalisation policy reform that was conceived and implemented from the year 2001 to 2007. The research extends the policy learning theory work of James and Jorgensen and others by more holistically explaining how policy knowledge, through policy learning, affects policy formulation, change, the direction of that change, and outcomes. To provide an investigative platform for this, the study aimed to capture the perceptions related to Russian policy learning and adaptation from three primary policy community groups which included Russian energy researchers, international industrial informants, and economists with a high degree of involvement in power sector liberalisation policy development. In the course of the research, policy learning causal 'moments' were identified in the form of synchronic and diachronic interrelated frameworks that indicated causal mechanisms and causal paths. The empirically derived research results were from conceptual, planning, and implementation processes used to diversify Russian policy learning, primarily from relevant, concurrent, international policy experiences and outcomes in Britain, and to a lesser extent, the USA.
\end{abstract}

Index Terms - liberalisation, policy causality, policy framework, policy learning theory, power sector, Russia.

\footnotetext{
${ }^{*}$ Corresponding author.

E-mail: dr.marcel.lamoureux@outlook.com
}

http://dx.doi.org/10.38028/esr.2020.01.0001

Received February 25, 2020. Revised May 01, 2020.

Accepted May, 17 2020. Available online July 31, 2020.

This is an open access article under a Creative Commons Attribution-NonCommercial 4.0 International License.

(C) 2020 ESI SB RAS and authors. All rights reserved.

\section{INTRODUCTION}

The focus of the research was on Russian power sector liberalisation from 2001 to 2007 as a case study M. A. Lamoureux, "Policy Learning Theory Derived from Russian Power Sector Liberalisation Experience," Ph.D. thesis, Glasgow, Caledonian University, Glasgow, Scotland, UK, 2012, which was then analysed to outline and then identify new categories and frameworks in policy learning theory. The proposed power sector reforms identified in the case study were broad, complex and unprecedented in Russia, and were widely regarded as necessary to provide a better environment for investment and global energy integration. Russian policy stakeholders studied and utilised international models to craft domestic policies aimed at liberalising the power sector. However, the following was unclear:

1. the quality and mechanism of policy learning

2. the type, content, and application of policy learning over time

3. potential policy change and direction of change

4. outcome as a consequence of policy learning

Accordingly, the Main Research Question (MRQ) was:

What are the perceptions of three policy community groups, which include domestic energy researchers, industrial informants, and economists, regarding the formulation, change, direction of change and outcome of Russian power sector liberalisation policy?

The literature review section describes conditions prior to liberalisation, and an overview of implementation status. The Russian and international liberalisation experiences are outlined. The methodology section describes the research method and techniques as well as the sampling method. The results section presents the synchronic and diachronic policy learning frameworks, including their causal, categorical 'moments' and relational properties. The discussion section presents the theoretical and practical implications of the frameworks in relation to extant frameworks. The paper concludes with a description of the policy theory implications of the research and recommendations for future research. 
II. LITERATURE REVIEW: AN OVERVIEW OF RUSSIAN AND INTERNATIONAL POWER SECTOR REFORM

A. Conditions prior to Russian power sector liberalisation

From 1992 to 2000 there were serious issues facing the power sector, such as, a significant decrease in capital investments for modernisation, and a sharp reduction in the commissioning of new capacity [1]. The power sector was being affected by the broader Russian economic crisis that:

"...created a very difficult situation in the industry. Inflation, non-payments, depreciation of assets, etc., interfered with the financial and economic activity of energy companies. All the indices of the industry gradually deteriorated and reached a critical level. The decrease in electricity consumption and high organisational and technical level of the [Unified Power System] UPS that had been achieved by the early 1990s somewhat mitigated the situation. However, the problem of equipment aging at power plants and networks grew increasingly urgent" [1].

Also, during this period, the power sector was largely a natural monopoly with vertically integrated companies having ownership of transmission, distribution, and generation functions [2].

In response to urgent problems in the power sector, the seminal law, 'About the Electric Power Industry' was proposed and approved in 2003. This law was part of the development of a new legislative framework built in part upon external liberalisation experiences designed to enable general industry goals, such as, energy security for Russia; reliable functioning of the power system; and cost minimisation $[1,3]$.

\section{B. Overview of Russian power sector liberalisation}

Although there were several contemporary reasons for power sector liberalisation that will be examined infra, the roots of Russian power sector reform initiatives may run deeper and be causally connected to previous Soviet era attempts at "market oriented reforms" [4] under the category of an "experimental initiative" $[4,5]$. The policy template for the power sector liberalisation initiative may have been formed under the previous Soviet system where reform "followed a broadly similar pattern of development (it is perhaps more correct to identify a pattern of limited growth and decline)" [4]. Soviet era reform, reflective of the description of Belyaev [1] supra, was focused on "particular industries or enterprises which have been experiencing specific difficulties..." [4].

Apparently in accordance with the approach taken with previous experimental initiatives, the Russian government developed medium and long-term economic policy reform programmes in 2000 and 2001 [6]. The two goals of the reform programmes were to increase private enterprise and investment [6]. The power sector represented the most serious problem for the Russian economy at the time because of inefficiencies and a deteriorating infrastructure [6]. Therefore, a primary goal for the sustainability of the infrastructure was to attract investment [7]. Linkages had been made between regulatory reform of the power sector, and the confidence of investors and potential entrants [6]. This vision of power sector restructuring included the deintegration of the Russian electric monopoly, RAO UES, and the ownership separation of the transmission network from distribution and generation [6]. Investment was a dominant internal motivation for Russian liberalisation of the power sector.

The liberalisation of the power sector in Russia should be conceived in the broader context of a transitioning economy, as well as policy development. A transitioning economy can be understood as evolving from a centrally planned economy to a market-based economy. In this context, the Russian power sector reform process was one element of an overall economic and political reform plan [8].

Russian power sector liberalisation was part of an international trend toward privatisation and liberalisation in the sector [9]. The Russian move to liberalise the power sector follows other international reform experiences led by Britain [10]. As such, power sector liberalisation was an innovative turning point for the evolution of the power sector toward establishing elements of competition [11]. It was posited that Britain, as an originator of power sector liberalisation policy, had that policy de-contextualised and institutionalised as global policy transfer occurred [12]. This was foreshadowed by Littlechild [13] who stated,

"In some respects, the circumstances of each developing country are different from Britain and from each other. Essentially the same principles of public policy apply... with appropriate modifications for the circumstances of each case, the policy of privatisation, competition, and independent regulation seems the right policy for developing countries too" [13].

This statement was indicative of subsequent international attempts to learn from and implement standardised power sector reform programmes which were patterned from Britain's leading experience [14, 15].

The Russian rationale for power sector liberalisation included internal motivations which, in addition to investment, included the need for higher levels of efficiency. However, there were external motivations as well, which included economic and technical interests. This was exemplified by Voropai and Kucherov, [16], who stated: "The goal of Russia and its Unified Power System (UPS) is to become an equal partner and major player in the European electricity market". This was indicative of European and (former Soviet) Russian interests in integrative energy cooperation [17,18]. Therefore, inasmuch as Europe followed the lead of Britain to liberalise electricity markets [19], and Russia had an interest in participating in the liberalised EU wholesale power market via transmission interconnections [16], Russian policy makers were also reacting to external political and business interests. Similar external incentives for Russian wholesale power market liberalisation were found in Russian economic and 
technical linkages with the Commonwealth of Independent States (CIS) and Asia [20, 21].

Russian motivations for power sector liberalisation and reform created an environment where policy makers became interested in learning from previous experiences, such as in Britain, which were considered optimal [22] Accordingly, the British liberalisation example provided a broad reform record of privatisation [23], regulation [13], competition [24] and innovative wholesale power market designs [25, 26]. Therefore, although future assessments would conclude that no single liberalisation example works in all circumstances [27, 28], Russian policy makers attempted to learn and integrate policy principles for the design and implementation of a liberalised power sector from Britain and other countries [29].

\section{Policy learning from international liberalisation} experiences

Russian power sector liberalisation policy can be tied directly to the effects of, and response to, the broader economic challenge faced by the country [30], however the application of reform was focused, rather than comprehensive as identified in this quote: "Russian policy makers have not taken a holistic view of the design of the energy markets. For these reasons, Russia has not evolved towards a new policy paradigm in all energy sectors" [31].

Although a broader implementation of liberalisation policy was not enacted in Russia, comprehensive and parallel sectorial liberalisation, especially with related industries, was a common theme found in other countries who have implemented reform programs prior to Russian implementation [31]. Regardless, external policy learning took place in Russia, and was part of the policy-making processes of power sector liberalisation. External experiences became objects of study in Russia, with the intent to compare and contrast the policy experiences in other countries with that occurring in, and considered for, Russia [32].

As the experiences of other countries became known and analysed, divergent views surfaced regarding the direction of power sector liberalisation policy, generally categorised as debates between the 'reformers' and 'opponents' [33] or characterised as 'reformers' and 'conservatives' by YiChong [28]:

"Moderate reforms were also the result of the conflicts between 'reformers' who were determined to bring Russian industries in line with the West and 'conservatives' who were not willing to risk the reliable supply of electricity".

This debate was reflected in more than 10 conceptions that were posited as power sector liberalisation and industrial restructuring possibilities [34], many of which were rooted in liberalisation experiences learned from other countries.

"Russia is drawing on the international experience of liberalising the electricity industry, but it is nonetheless a long and complicated process. In addition, no well-defined system exists for creating an optimal electricity sector, as the results of liberalisation in other countries are controversial" [35].

This quote from Kurronen, [35] supra, encapsulates the fact that Russian policy-makers have studied international experiences from conception to implementation, but that apparently no external liberalisation experience or policy standard is a perfect 'fit' for the Russian context. In contrast, Pittman [10] observed that the core objective of Russian power sector liberalisation is very similar to external experiences:

"The goal of the [Russian] restructuring strategy is the same as that behind the application of this now-standard reform model in other infrastructure sectors in other countries: to replace, where feasible, the old regulated, state-owned monopoly enterprises with deregulated, privately owned enterprises, competing among themselves to operate and invest efficiently and provide outputs at the lowest efficient prices".

Much of the policy debate surrounding implementation of liberalisation was centred around the components of 'conceptualisation' based on external experiences, and its integration with the realities of the Russian power system, structure, and end goal which were modified over time. Although it is unclear regarding the actual quantity or quality of Russian external power sector liberalisation policy learning, the manifestation of domestic reform policy, its effects, and change have allowed for some visibility into the policy-making process.

\section{METHODOLOGY}

\section{A. Research Method}

Case study methodology was chosen as a best fit for the research based on the premises that a "...case study is a research strategy which focuses on understanding the dynamics present within single settings" [36] and that "A single case study is still a single-shot affair - a single example of a larger phenomenon" [37]. At the beginning of the research there was interest by the researcher to determine if the case under investigation could yield hypotheses or theories that may be externally applicable, which would need to be included within the limited research purview and subsequent results. The rationale for this was based on the inherent economic and policy influence that Russia had within the contiguous Commonwealth of Independent States (CIS) at the time [38], the increasing power grid integration with Europe [16], and subsequent crossborder influence on policy formation and implementation. However, after a deeper review of scholarly, case study research, the researcher determined that the "case study should be guided by the research question" [39] and that the MRQ could be answered more profoundly by focusing on the internal validity of the research to be undertaken. This decision was substantiated by Gerring [37]: "Often, though not invariably, it is easier to establish the veracity of a causal relationship pertaining to a single case (or a 
small number of cases) than for a larger set of cases." Therefore, the researcher determined that a single-case study, as opposed to a cross-case study would provide a better means to identify and investigate specific causality and change associated with it. Gerring [37] substantiated this further by drawing a contrast between cross-case studies and single-case studies:

"cross-case studies are likely to explain only a small portion of the variance with respect to a given outcome. They approach that outcome at a very general level. Typically, a cross-case study aims only to explain the occurrence/non-occurrence of a revolution, while a case study might also strive to explain specific features of that event - why it occurred when it did and, in the way that it did. Case studies are thus rightly identified with "holistic" analysis and with the "thick" description of events".

\section{B. Choice of analytic induction}

The process of discovering emergent theory arising from qualitative interviews was aided by the use of analytic induction [38, 39, 40, 41]. Accordingly, the researcher interpreted data [42] without developed hypotheses prior to the collection of data. The researcher collected and analysed perceptions that provided conceptual insight into the mechanics of policy learning inasmuch as "Concepts are developed inductively from the data and raised to a higher level of abstraction, and their interrelationships are then traced out [41]. Additionally, analytic induction is an approach where "...theory comes last and is developed from or through data generation and analysis" [42].

\section{Sampling method}

The researcher conducted 20 semi-structured, indepth interviews, composed of 18 distinct participants and 2 follow-up respondents. The data samples were from respondents who comprised three issue-related policy community groups. The policy community groups were elements of a homogenous sample of a power sector liberalisation 'policy issue network' as defined by Rhodes and Marsh [43], and henceforth referred to as the 'policy network'. The selective and theoretical sampling was guided in part by the conceptual developments from the data that provided the first insight into emerging theory and frameworks. The concepts, and subsequent research direction provided guidance for the selection of additional interviewees. As the primary aim was "not to generalise to a population, but to obtain insights into a phenomenon, individuals, or events"..."then the researcher purposefully selects individuals, groups, and settings for this phase that maximise understanding of the underlying phenomenon" [44]. Individuals were chosen to be interviewed because of their prominence in the research area and because they were "information rich" [45].

The researcher's approach to both the initial method of interviewee selection and subsequent addition of interviewees was reflective of the works of Carlsson [46], and $[47,48,49]$ in the area of policy networks.
Carlsson [46] stated that "the network perspective can be distinguished by its (a) non-hierarchical way of perceiving the policymaking process, (b) its focus on functional rather than on organisational features, and finally (c) its horizontal scope." In this statement, Carlsson [46] was attempting to build upon the assertion by Hanf and Scharpf [47] that "the term 'network' merely denotes, in a suggestive manner, the fact that policymaking includes a large number of public and private actors from different levels and functional areas...". Therefore, it can be assumed that, although a policy network has a purpose holding it together, it also represents a diversity of members focused on a single policy problem. Carlsson [46] also suggested that "policy networks can be regarded as a broad generic category" and "can be divided into numerous subcategories". Kenis and Schneider, [48] also posited that "A policy network is described by its actors, their linkages and its boundary." Building upon this, the researcher agreed with the salient, and contrasting point made by Jordan [49] when he suggested that "the policy network is a statement of shared interests in a policy problem." A policy community, as a sub-set of the network, was defined as a group of "actors within the network" [50]. Hogwood in Jordan [49] further defined policy community as a concept describing "shared experience, common specialist language, staff interchange, and frequency and mode of communication." Accordingly, the researcher identified and assembled a sample of a policy network composed of policy communities. The result was the identification and sampling of three emergent policy communities:

1. Domestic energy researchers (Russia)

2. Industrial informants (Russia and external)

3. Economists (Russia and external)

These groups shared a distinct community interest and perspective in power sector liberalisation policy and had active or passive linkages and participatory intersections to compose an effective sample of a policy network involved with Russian and international policy learning and power sector liberalisation. Within the communities, the researcher utilised these criteria for inclusion and exclusion:

1. A perspective relevant to the research question.

2. Prominence in their policy community area of interest.

3. Active or passive linkages to the policy network focused on Russian power sector liberalisation.

Consideration was given regarding the level of effectiveness of the emergent communities on policy decision-making. This consideration fed into the above criteria for inclusion and exclusion inasmuch as the communities were relevant, prominent, and clearly linked to the broader policy network that had effect on policy decision-makers. For example, the communities tended to be relationally self-supporting, and had impact on the direction and scope of power sector liberalisation policy in Russia. This relationship became clearer as the researcher conducted interviews and became more aware of the 
broad learning relationships that were taking place across the network sample. This was led in part by the scientific activity of the Melentiev Energy Systems Institute (ESI) in Irkutsk, Russia, which was directed toward determining the scientific foundations and mechanisms for the implementation of Russian energy policy at national and regional levels. Since 2001, the ESI has been a leader within the liberalisation policy debate in Russia, and has contributed to the formation, definition and activity of the policy network and subsequent communities involved with relevant policy research, influence and implementation. This is explicitly apparent in the ESI's role in hosting international conferences such as the 'Liberalisation and modernisation of power systems' conference that began in 2001. In addition to strengthening the human network involved in power sector liberalisation research, products of the ESI liberalisation conferences were subsequently collected. Published proceedings and policy recommendations were provided to Russian and international policy decision-makers and leading power sector business interests. In addition to the liberalisation conferences, the ESI led joint Russian-European Union (EU) policy projects in the areas of 'coordination, operation, and emergency control of EU and Russian power grids' and 'technological problems of liberalised electric power system control', - both of which were embedded in the Russian power sector policy debate and decision process.

With the ESI domestic researcher 'community' as an emergent leader of the policy network, additional research and interviews revealed the linkages that existed between the other communities and members of the network. Most of the industrial and economic community members were influenced in some way by the work of the ESI, either by attending ESI liberalisation conferences, receiving ESI liberalisation policy publications, or indirectly, by having a role in determining international power sector liberalisation trends.

Importantly, Marsh and Smith, [50] found that the view of policy decision-makers "was clearly shaped by the structures of the policy community" (p. 17), and that "policy outcomes were shaped by the policy process and the nature of the community" (p. 17). This finding by Marsh and Smith, [50] substantiated the researcher's rationale for identifying prominent policy communities involved in Russian power sector liberalisation debate, as a data source.

As a follow-on from the establishment of a method for sample selection, the researcher wanted to gather a broad range of perceptions from the distinct policy communities to provide a high degree of richness in accumulated data. Therefore, the researcher chose purposeful, maximum variation sampling $[51 ; 40 ; 41]$ as a means to choose interviewees for inclusion. Realistically, the selection of interviewees in the three interviewee groups represented a balance between interview feasibility due to time and distance, response to interview requests, the need to gather diverse perspectives from prominent policy community members, and the terminus dictated by data saturation. This sampling technique, therefore, manifested itself in the range of selection of Domestic Energy Researchers within the context of their diverse fields related to the research question and their departments at the ESI; Industrial Informants as represented by their range of experience and policy community relevance (individual and corporate representation); and Economists by their approach to the subject and range of research or international experience with policy learning and adaptation.

Additionally, selective sampling [52] was used initially to enable conceptual development followed by the use of theoretical sampling [52] as concepts and themes provided insight into the choice of additional sampling. A metasampling criterion for all participants was their range of horizontal linkages to the policy network, that at its core would address the research question.

The researcher followed a criteria of qualitative data analysis by adhering to data saturation as a sampling and analysis mechanism for naturally terminating the collection of data samples. This was substantiated by a survey of applicable literature regarding data saturation, inclusive of definitions of saturation, qualitative data saturation experience, sample size analysis based on documented British Ph.D. theses, and principles of data saturation. Based the experience of the researcher, whereby the study reached a point in sampling where additional interviews did not yield new categories, the researcher was confident that the number of interviews, the quality and quantity of data, and its homogeneity, naturally defined a termination of sampling. The survey of literature substantiated this assessment of the researcher by clearly indicating that the number of samples collected to answer the research question and to reach data saturation exceeded the minimum documented and recommended samples for a qualitative study, regardless of the methodology utilised.

\section{RESULTS}

A. Analytical policy learning frameworks for Russian power sector liberalisation policy

Significant findings of the research were abstracted, analysed, and categorised in the form of diachronic and synchronic policy learning theoretical frameworks. The emergent frameworks are indicative of analytical induction which is teleological inasmuch as it is a search for an end point in theory which is intrinsic in character. Theory assumes the existence of, and the ability to, discover the essential character or nature of the object of research.

B. Synchronic policy learning theoretical framework

A synchronic policy theoretical framework emerged from the research findings that actualises and analyses policy 'in the moment'. The synchronic policy framework, as an ontological construct, is concerned with policy at a specific space and time, exclusive of policy antecedents. The theoretical framework can be applied as a means to 
actualise policy, in the sense of it existing objectively, as a teleological process, and to analyse policy at a specific space and time.

\section{Diachronic policy learning theoretical framework}

A diachronic policy theoretical framework was identified from the research findings that actualises and analyses policy 'over time'. The framework, as an ontological construct, is concerned with policy change 'over time', inclusive of policy antecedents. The theoretical framework can be applied as a structure to create policy, in the sense that it is the vertical causation of policy existence, as a teleological process, and to analyse policy 'over time'.

\section{Analytical overview of the frameworks}

Previous policy learning scholarship demonstrated that theoretical, directional policy frameworks can be empirically derived in the areas of policy transfer [53] and policy transfer analysis. This has also been true in the development of sub-group policy learning frameworks [54]. However, there was a lack of organic relationship, temporality and reflexivity built into all of these frameworks. The frameworks derived from the research findings demonstrate both an internal, and external reflexive process. The synchronic policy theoretical framework is introduced first, as a means to present the theory that emerged from the data. The synchronic framework was reified prior to attaining all of the data, inasmuch as it was treated as an abstraction that was substantially existing and was then used to reflexively analyse unorganised data and to develop the meaning and properties of theory. Therefore, the synchronic framework logically provides the presentational systemisation of the research data.

There is an intrinsic relationship within the synchronic and diachronic theoretical frameworks. The three subcategories of the Synchronic framework are the concept, planning and implementation that emanate from the original policy noumenal ideation. The sub-categories are directional, and each is assumed by the precursor, although they have distinct starting points in the noumenal, conceptual starting point. An important new finding in the research was the emergence of not only a continuum, or planned process involved with power sector design, but the importance of including the core categories in every actualisation and application of policy change. Surrey [5] indicated that the power sector liberalisation process in Britain was an experiment, and the findings of the research indicated that due to the level of previous international experience, the Russian process integrated conceptualisation into planning and implementation. As the process was implemented, as a retention of experimental elements [4], circularity leads back to conceptualisation as policy is required to evolve. Therefore, synchronic and diachronic policy theoretical frameworks are reflective of the primary categories, relationships, and directionalities which have emerged from the research. The sections, infra, review the core categories, and formal sub-categories within the analytical construct of the synchronic policy theoretical framework.

The emergence of frameworks from the data has constructed categories which comprise policy phenomenon, policy substratum and policy superstratum 'meta-moments' which then existentially define or reflect an intelligible grounding in the form of the policy noumenon. Patterns which have emerged provide a teleological basis for policymaking inasmuch as policy learning is, in a philosophical sense, a phenomenal starting point for diachronic policy creation, and policy diffusion is the effect of policy learning. The research indicated that policy learning is an on-going, reflexive process which not only studies national and international

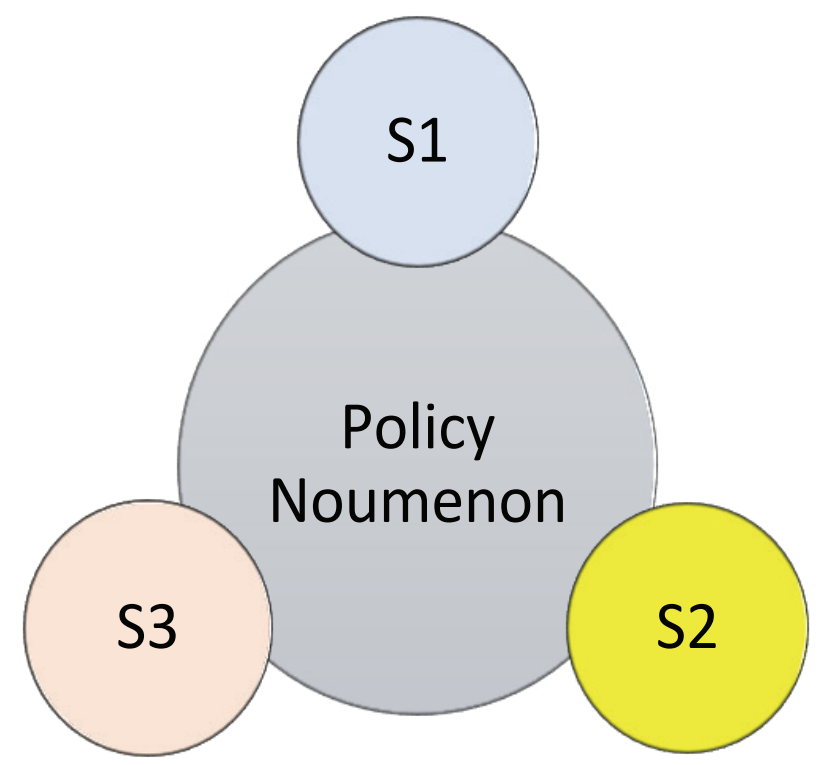

Figure 1. Synchronic Policy Framework.

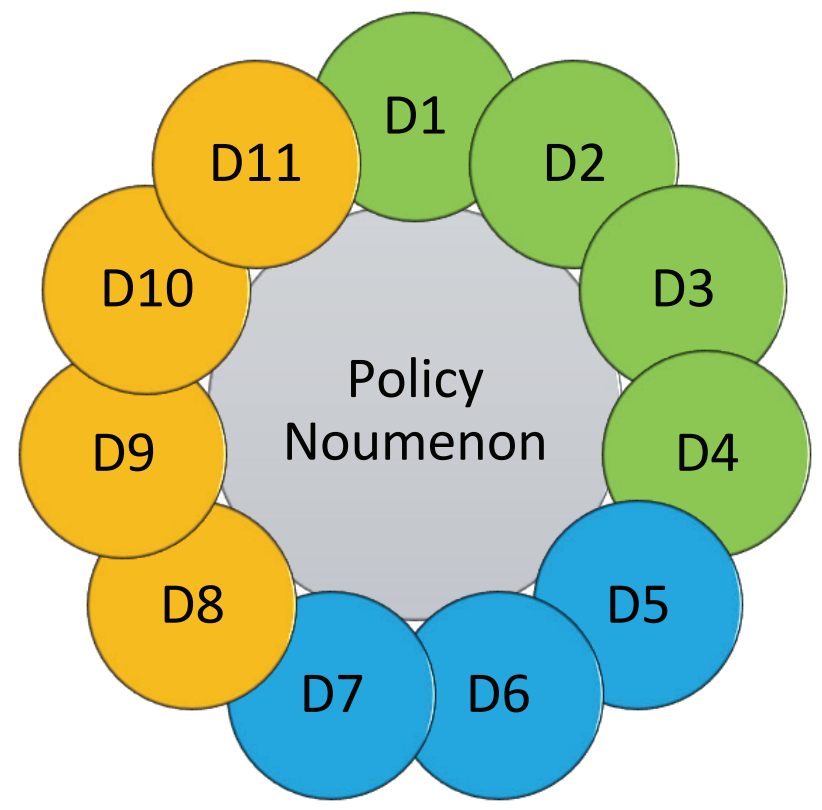

Figure 2. Diachronic Policy Framework. 
policies, but also accounts for the praxis of the policy area under review or intervention. Policy learning, as a proactive learning process, has a starting point which is an adaptation of policy and praxis, rather than transferential learning. Indeed, the research findings indicated that there can be variable conditions for policy learning inasmuch as contextual conditions vary according to national ethos and physiography.

Policy learning can be applied as a synchronic analysis method diachronically, which should measure micro and macroeconomic effects of policy during and after policy implementation. Policy diffusion, as a subset of policy learning inasmuch as diffusion occurs after policy learning, was found to be derived from multiple sources, at synchronic periods of time.

The emergent synchronic policy framework, as illustrated in Figure 1, infra, was used to analyse the diachronic policy outcome 'in the moment'. Although the original Russian concept of power sector reform in favour of higher investment, as the starting point of the diachronic policy phenomenon is immutable, as it was created at a moment in the past, the synchronic policy phenomenon is mutable, as it is created 'in the moment'. Russian policy makers have utilised the synchronic policy phenomenon cycle to measure the diachronic policy outcome against the original Russian diachronic policy concept, and on-going power sector conceptual developments outside of Russia. The categories in the frameworks relate to each other and relate to the distinct noumenon and phenomenon of emergent policymaking.

E. Synchronic policy theoretical framework moments relational properties: synchronic policy phenomenon meta-moment

\section{S1. Conceptualisation}

The research findings indicated that policy learning is formed by stages of activity. These stages are moments, in the sense that they are constituent elements of a complex process. Conceptualisation is inclusive of planning and implementation inasmuch as the latter two moments are objects of initial conceptualisation. Each moment, however, assumes the former, inasmuch as planning is a coming into being of a concept or set of concepts, and implementation is a coming into being of a concept or set of concepts and planning. This reasoning establishes the intrinsic relational circularity and extrinsic relational circularity whereby implementation is a means of re-conceptualisation 'in the moment'.

Conceptualisation of policy provides for contextualisation in the sense that policy can be conceived within the endogenous context of policy implementation, but also in the context of exogenous applications. Policy conceptualisation is temporal in the sense that policy learning focuses on previous as well as on-going, extant policy examples. Policy formation has philosophical foundations with dialectical mechanisms, as a causal force, and is used as a remedy for perceived crises in an effectual sense. The effectual teleology involved with this suggests the need for reflexivity, inasmuch as supplying a remedy solicits an enquiry about whether the remedy can, or has, fulfilled the original intent. Policy implementation can be experimental, however, measurement of policy has higher validity 'in the moment' and has diminishing validity as predictive mensurative analysis is applied. This is particularly the case when the level of experimentalism is high, or where contextualisation of previous policy is significantly divergent from the original concept. Policymaking concepts include equilibria for policy outcomes, as well as short and long-term goals and macroeconomic outcomes dependent on the policy outcome.

Additionally, the crafting of conceptualisations should consider all short and long-term objectives to avoid a flawed concept, and a flawed policy outcome. Adequate compositions of policy subgroups should ensure thorough debate over all subject elements at the policy concept level. Policy conceptualisations should include assessments of current deficiencies as well as short and long-term policy effects. Policy conceptualisation has also included, as a precondition for policy success, on-going adaptation to change over time. This indicates that a legal structure should be in place to guide and analyse policy 'in the moment' to account for, measure and assess policy change over time. Importantly, policy conceptualisation should transcend the subject under study, and consider wider social benefits. Some areas of policy conceptualisation can be considered standardised, and some primarily contextualised. Standardisation should include the structural means for policy planning, implementation, and the creation of general guidelines.

\section{S2. Planning}

Conceptualisation of policy is a process whereby the basic outline of goals and predicted outcome are agreed upon. The planning moment follows the conceptual moment inasmuch as planning approaches the topic with more of an applied, logical thought process which is built upon knowing. Conceptualisation defines policy motivations, and planning centralises those motivations as the policymaking process unfolds. The end goal of policy implementation has a direct effect on the initial moments of policy conceptualisation and planning. If a policy goal is a transitional process, whereby the initial motivation will not be satisfied until a period of time has passed, other measures can be taken to encourage beneficial outcomes in the interim. This is explained in the research findings where policy solutions were categorised and implemented on different timelines. Policy planning should delineate all aspects required for policy implementation in the context of having a successful policy outcome.

\section{S3. Implementation}

Policy implementation can have planned and unplanned consequences. Such consequences can include internal 
problems which include delays and unforeseen influences which affect policy implementation and outcome

These consequences are effects of policy outcome. These effects can include negative outcomes which also can be categorised as policy devolution. This also indicates the need for regular assessments of policy outcomes, effects, and reconceptualisation to possibly revise the composition and direction of policy. The research findings suggested that there can be non-compliance of policy because of pre-existing conditions that make policy implementation impracticable. Policy evolutionary development and outcome over time requires a continual review and ongoing learning process to detect unforeseen influences. Internal policy micro-developments can evolve, affecting macro-conditions, requiring a governing body to regularly intervene in policy outcome.

\section{Section Summary}

The research findings, at the level of inductive theory development, indicated that there is a directional linkage between policy conceptualisation, planning and implementation. Policy conceptualisation includes the conceptualisation of the planning and implementation process which should account for short and long-term policy goals. As policy is implemented, periodic assessment and analysis are necessary to detect or correct unforeseen evolution and devolution. As a consequence of policy analysis 'in the moment', the diachronic policy outcome can be re-conceptualised, and enter into a synchronic policy framework actualisation and analysis system.

F. Diachronic policy theoretical framework metamoments and moments

The diachronic policy theoretical framework is composed of the meta-moments of noumenon, phenomenon, substratum and superstratum. As illustrated in Figure 2., the constituent, categorical moments are the stratal elements of the meta-moments.

\section{A. Diachronic Policy Phenomenon Meta-Moment}

The diachronic policy phenomenon meta-moment is the perceptible manifestation of the diachronic policy noumenon meta-moment. The noumenon provides the intelligible grounding of logical policymaking precepts. Although the noumenon in this sense holds a 'place' as a 'moment', it is a noetic cause that permeates the whole of the process. Therefore, noumenon is not delineated as a distinct 'moment'. In contrast to the noumenon, the policy phenomenon is the perceptible event, circumstance or experience that provides grounds for, and stimulates, learning.

\section{D1. Policy learning}

Policy learning is composed of multiple sources of input, comprising policy diffusion. Policy learning is composed of both internal learning and external learning. Existing conditions are assessed in the policy learning process which include motivating factors and social and physiographic concerns. External policy learning provides perspective on internal concerns, as well as value attained through understanding previously conceived, planned and implemented policies. The research findings have indicated that policy learning precedes policy diffusion. However, prior to the assimilation of knowledge, policy information is imperfectly known, and mutated as the policy concept is learned.

\section{D2. Policy transmutation}

Policy transmutation is the process of learning extant policy in an imperfect way. The research findings indicate that policy is learned from endogenous incentives, or from exogenous developments. Policy networks have differing visions of policy conceptualisations, and that policy transmutation occurs as the policy concept is understood and contextualised to the receptor's ethos. Transmutation of policy, as an imperfect understanding of policy, begins with the policy model under review. Policy transmutation, as a consequence of policy learning, begins at the point when policies under review are considered for adaptation.

\section{D3. Policy trans-adaptation}

Policy trans-adaptation follows a transmutation of an external policy concept. The external concept is not formed until a full concept has formed from policy learning, transmutation, trans-adaptation and diffusion. Trans-adaptation is the process and effect of policy learning of an imperfect concept. The process and effect are both individual and institutional. Trans-mutated policy concept may be flawed, or multi-dimensional, and subject to multiple points of view. Policy adaptation is subject to changing conditions. These changing conditions can be in the endogenous policy ethos, or by learning from the diachronic external policy ethos. Policy adaptation is the final step prior to policy diffusion, inasmuch as once the policy concept is imperfectly learned, thus mutated, and trans-adapted as an individuated idea or institution, policy diffusion occurs.

\section{D4. Policy diffusion}

Policy diffusion is a contingent process and effect. Diffusion is contingent on policy learning, transmutation and trans-adaptation. The research findings indicated that policy is diffused because of internal motivations or because of external impetuses. Diffusion of policy is primarily within the conceptual moment of policy inasmuch as it has not yet been manifested as a nomological process, such as a policy planning moment. The research findings indicated that the integration of external, diachronic policy with endogenous conditions, creates a policy coalescence. This policy coalescence creates a new concept which has originated from elsewhere but is developed from within. Therefore, at the full level of conceptual development, which is also the full level of the policy phenomenon, the next meta-moment of policymaking comes into being: the policy substratum.

\section{B. Diachronic policy substratum meta-moment}


The policy substratum meta-moment, composed of the stratal moments of a diffused, external policy concept, paradigm and network, is in relation to both the policy phenomenon, which is an event, circumstance or experience, and the policy superstratum. Inasmuch as the policy superstratum is the outcome, or substance of policy in the sense that it has independent existence and is acted upon by redundant causes, the policy substratum is the event or causes which act upon it; the changes occurring within it; and the attributes which inhere in it. The policy substratum is 'en prévision' in the sense that it is in a state of readiness for the actualisation of policy outcome.

\section{D5. Policy external concept}

The external concept, as indicated by the research findings, is a fully actualised concept which was learned imperfectly, mutated and adapted to the endogenous ethos. As such, it is the starting event in the substratum whereby it comprises the policy paradigm and policy network. The external concept is the starting event that acts upon the outcome of policy. The external concept is the starting point for policy planning, as it provides a logical template for policy actualisation. The research findings revealed that once a concept is actualised, planning begins in the form of formulating structure and temporal, parametric considerations. The external concept is applied to the original motivating factor for the creation of policy. The external concept is paradigmatic, inasmuch as it is a pattern, example or model which effectively explains a complex policy process, idea or set of data.

\section{D6. Policy paradigm}

The policy paradigm emerges from the policy external concept. The policy paradigm is the external concept's lexical meaning inasmuch as the concept is the basis upon which the policy model is created. The research findings have indicated that the policy paradigm is composed of the external concept, and the endogenous ethos. The research interviews indicated that information which was learned was only relevant inasmuch as it pertained to the defined ethos in the context of policymaking. The policy paradigm addresses overall policy concerns which transcend the target policy area. The policy paradigm, as a more complete actualisation of policy, is reflective of the motivation for policy creation, and the process to actualise policymaking. The policy paradigm becomes the template for the creation of the policy network inasmuch as the policy network is a group or system of interconnected or cooperating individuals. The policy paradigm provides nodal interconnections for policy network activity in the sense that nodes are interconnected points of concentration which are actualised by the policy paradigm. To explain, arising from general policymaking motivations, a deductive process unfolds, whereby more specific areas of enquiry and actions emerge. These areas of concentration provide an indication of participatory enquiry and activity.

\section{D7. Policy network}

The nodal interconnections for a policy network begin prior to the policymaking process, as a network substratum, but only become fully actualised as a network once the policy paradigm is fully actualised. In this sense, one can logically comprehend that the first node, prior to the policymaking process, is the policy noumenon metamoment. The policy network becomes actualised as the diachronic policy framework becomes actualised. In this sense, policy nodal interconnections evolve within the diachronic policy framework and provide the organic means of policymaking enquiry and activity. Policy nodal interconnections, as evolving policy networks, are organic in the sense that they are made up of systematically interrelated parts. The research findings have indicated that a policy network includes participants who are part of the endogenous ethos, and extraneous ethos, as long as the participation is relevant to the policy framework. The research findings indicated that categories of policy network participation exist. They are the inveteracy, who are established in the policy process over a long period of time, and the ephemeral, who either by policy framework design or external causation, interpose policymaking change for a brief period. The policy networks, as defined this way, can be individuals, groups, institutions, and referential ideas. Endogenous and extraneous policy outcomes are ideas that become part of a policy network. The policy network provides an actualisation for policy outcome 'over time' and 'in the moment'.

\section{Diachronic policy superstratum meta-moment}

The diachronic policy superstratum meta-moment, composed of the stratal moments of policy-networked actualised policy outcome, evolution, devolution and measurement, is causally contingent upon the policy substratum and the policy phenomenon. However, as the policy outcome interfaces with existence and time, and is then subject to evolution and devolution, it becomes independent of the policy substratum and policy phenomenon. The research findings indicated that the policy outcome can be a result, a consequence, but more importantly, a solution which is subject to change 'over time'.

\section{D8. Policy diachronic outcome}

The policy diachronic outcome has its basis in the policy network. However, prior to policy interface with existence, the policy outcome is more correctly to be considered a policy dénouement, in the sense that it is a proposed solution which needs to continue to unfold as it interfaces with existence. The dénouement is the final revealing of the policy solution as it is actualised 'over time' upon the policy target area. The policy outcome is the effect of policy 'over time' and 'in the moment'. The research findings indicated that either by design, or unexpectedly, policy can be applied in stages with the intent to phase-in the policy outcome. Therefore, 
the policy outcome is a diachronic process to reach the final policy goal and is also in a diachronic process as it reaches the policy goal. In this sense, the policy outcome is in an ever-changing state which is subject to the causation of the policy framework but is independent in the sense that it changes 'over time' as it interfaces with existence. The research findings indicated that both endogenous and exogenous factors influence the policy outcome. Logically, as the policy network actualises the policy dénouement and applies it to existence, the policy outcome is then in a state of ontogeny, in the sense that it has entered a life cycle subject to time and space, and therefore, evolution, in the sense that it is in a continual process of development.

\section{D9. Policy evolution}

Within the context of policy diachronic outcome, which is subject to space and time, policy evolution is a phylogenetic process. Policy evolution is phylogenetic inasmuch as it is the historical development of the policy outcome. The policy outcome is never quiescent and can only be measured in reference to its historical effect, and effect 'in the moment' which becomes less valid with change 'over time'. The research findings indicated that policy evolution reveals positive aspects of policy implementation. Negative aspects of policy evolution can also be known. The research findings indicated that policy evolution is intrinsic to policymaking inasmuch as policy is subject to space and time, but also extrinsic in the sense that the policy external concept, as applied in the new ethos, can provide an evolutionary structure in the form of implementation stages. Additionally, the interaction of the synchronic theoretical framework promotes evolution based upon the measured amount of deviation or divagation from the original concept, or the need for deviation or divagation from the original concept because of empirical evidence which promotes such change. Any aspect of policy evolution which is measurably degenerative is categorised as policy devolution.

\section{D10. Policy devolution}

Policy devolution follows the emergence of policy evolution. As no policy is conceived perfectly, no policy can be implemented perfectly in the sense that policy cannot be complete in all respects, and without defects. Therefore, policy outcomes are subject to devolution whereby there is a degeneration of policy evolution. The research findings indicated that there can be intentional devolution of policy outcome. Additionally, policy devolution can take the form of unforeseen effects. These examples of policy devolution describe a process whereby the evolution of policy outcome degenerates from the original policy concept. The devolutionary process leads to a state of policy involution. Policy involution is a retrograde or degenerative change. The research findings have indicated that policy involution occurs after a period of policy devolution, particularly if the policy outcome framework was ill-conceived, and if policy intervention was non-existent or non-effective. From conception to devolution, policy measurement is a diachronic process. Policy measurement reaches a state of liminality, inasmuch as it is at a boundary or transitional point between two conditions, in the sense that it is optimally positioned between what is and what could be. This is also a liminal point between positive and normative aspects of policy. In this sense, policy measurement is circumferential.

\section{D11. Policy measurement}

Mensuration is intrinsic to policymaking in the sense that policy conceptions are formed by measuring a need. All aspects of the policymaking process are in relation to that initial measurement. The policy diachronic theoretical framework is reflective of the mensurative process whereby the need is addressed by conceptualisations and structures necessary for a remedy in the form of a policy dénouement. Once the policy dénouement is applied to existence, an effective mensurative process begins. The research findings indicated that once policy is implemented, a continual review of the policy is necessary, where policy devolution is measured. The research findings indicated that policy mensuration includes all aspects of policy creation and actualisation, including extrinsic policy change over time, and its relevance to the endogenous policy. The measurement of policy is at an optimal point between the relationship of the policy outcome, which is a dependent variable, and policy intervention, which is an independent variable.

\section{Section Summary}

Russian policy creation and application can be conceived as an expanding sphere with a centrobaric centre, in the sense that the policy noumenon provides an intellectual centre of gravity for the diachronic policy theoretical framework. The policy noumenon is also emanative, in the sense that the integrity of the noumenon is perceptible in the policy stratal moments. The stratal moments comprise the policymaking strata of policy meta-moments, the noumenon, phenomenon, substratum and superstratum. The moments of the policymaking framework are directional and represent an actualisation of policymaking elements 'over time'. The diachronic policy framework provides the creation and implementation of policy 'over time', and the synchronic policy theoretical framework provides the analysis and actualisation of policy 'in the moment'.

The interrelated frameworks, and their components, provide the basis of new theoretical policy learning findings derived from Russian power sector liberalisation policy experience. The next section builds upon this analysis and assertion by examining the noetic and phenomenal implications of the frameworks as well as a focused identification of where new knowledge is being applied with reference to relevant, extant literature. 


\section{DisCUSSION}

\section{A. Gaps in policy learning theory and implications of} the frameworks

In the course of examining literature related to policy learning during and after the period of research, the researcher became sensitive to a theme found amongst several articles and a book. This recurring theme identified a gap in research and knowledge, which, in turn, refined the focus of the MRQ. The following quotes provide references to a need to conceptualise, study, analyse (frame) the process and effects of policy learning in the context of policy implementation over time.

1. "Policy learning is a concept that is advocated but not adequately conceptualised" [55].

2. 'the use of 'policy transfer' to explain 'policy change' and policy 'success' or 'failure' does not adequately separate the policy 'success' or 'failure' being explained from processes of "policy transfer'"... "researchers may be better off using alternative theories focusing more directly on the effects of learning processes or styles of policy-making on policy outcomes" [56].

3. "In discussions of policy diffusion, particularly through the adoption of market reforms in the developing world, learning from the experience of others emerges as a plausible hypothesis, but it is clearly yet to be supported by empirical research" [57].

4. "Explanations of the policymaking process rest in theories and models, which should be, but typically are not, grounded in a framework" [58].

5. "...a deficiency of current policy theory is the inability to explain how policy knowledge affects policy formulation, change, the direction of that change, and outcomes" [59].

6. "The overarching concern is to understand how knowledge in the process guides our knowledge of the process and examining the utilisation of policy analysis and evaluation allows scholars to bridge the divide. There must be a 'perpetual 'back and forth' between images of the whole and particular details of time, place, and figure,' if policy scientists are to draw conceptual maps of the process and solve problems within the process" $[59 ; 60]$.

Sabatier [61] indicated that The Stages Heuristic: “... divided the policy process into a series of stages-usually agenda setting, policy formulation and legitimation, implementation, and evaluation-and discussed some of the factors affecting the process within each stage. The stages heuristic served a useful purpose in the 1970s and early 1980s by dividing the very complex policy process into discrete stages and by stimulating some excellent research within specific stages-particularly agenda setting" (p. 6).

However, serious shortfalls were experienced with this framework according to Sabatier [61]: "It is not really a causal theory since it never identifies a set of causal drivers that govern the policy process within and across stages.
Instead, work within each stage has tended to develop on its own, almost totally without reference to research in other stages. In addition, without causal drivers there can be no coherent set of hypotheses within and across stages" (p. 6).

\section{B. Implications for policy actualisation and analytical} functions

Once a policy is actualised, as a diachronic process, policy intervention 'in the moment' in the form of analysis and actualisation can take place. As a policy actualisation mechanism, the synchronic framework provides a means to:

- re-apply the intelligible grounding of the policy.

- have an interventional interface, to provide change in the policy according to its current existence.

- re-conceptualise, as an effect of mensuration.

- plan, according to the re-conceptualisation.

- implement, according to the re-conceptualisation and planning.

The analysis function of the synchronic framework inasmuch as it demonstrates the systematic enquiry of the life cycle of the policy as a single organism with component parts without reference to its antecedents. As a policy analysis mechanism, the synchronic framework provides a means to analyse the temporal life cycle of policy as a single organism. This includes:

- the condition and effect of the intelligible grounding of policy.

- the frequency and level of analytical interface with existing policy.

- conceptualisation status based upon current mensuration.

- the condition and effect of planning based upon the original conception.

- the condition and effect of implementation based upon the original concept and plan.

As illustrated in Figure 3., infra, the synchronic framework interfaces with the diachronic framework to

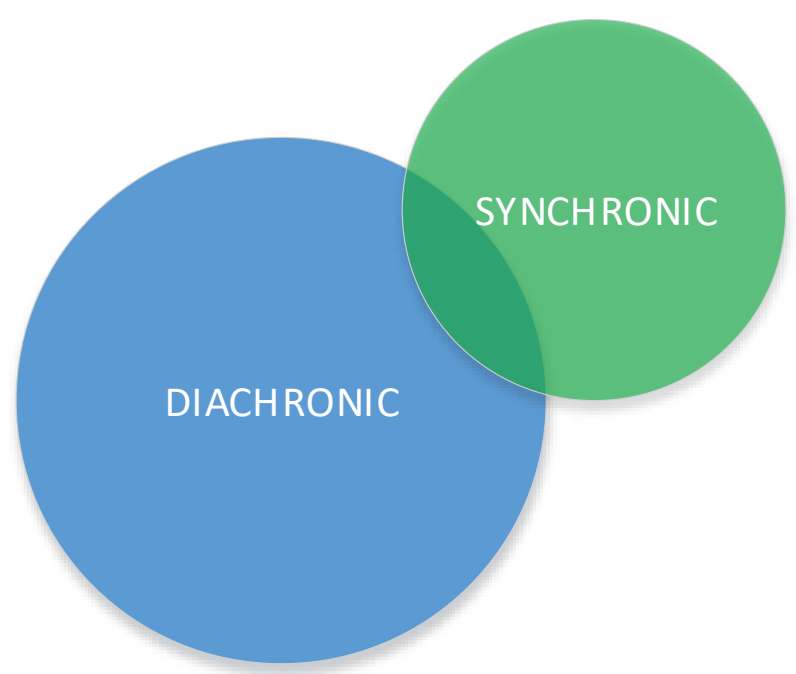

Figure 3. Synchronic and Diachronic Interface 
provide actualisation and analysis 'in the moment'.

The diachronic framework provides a means to actualise and analyse policy 'over time'. The actualisation function of the diachronic framework demonstrates the actualisation of components 'over time'. Each level assumes the previous actualised moment. As a policy learning actualisation mechanism, the diachronic framework provides a means to actualise policy 'over time', in the sense that the original noumenon and phenomenon are immutable, as they exist in the past. As the diachronic framework moments become actualised, the policy outcome becomes independent of the original concept. The diachronic policy outcome becomes existential 'over time', and only becomes cognitively regrounded when interfaced with the synchronic framework.

The diachronic framework demonstrates the systematic enquiry of the life cycle of the policy as a group of causally related moments. The diachronic framework is a mechanism to analyse the origin and evolution of the policy life cycle. The synchronic framework is dependent on the existence of the diachronic framework inasmuch as the synchronic framework becomes actualised when interfaced with an existing policy which was developed 'over time'.

\section{Implications for policy theory and analysis}

The effective importance of the synchronic and diachronic frameworks begins with the composition and integrity of the intelligible grounding of the policy phenomenon. The noumenon, as the intelligible grounding of policy, should dictate the perceptible moments of policy.

Policy theory was defined as "the total of causal and other assumptions underlying a policy" [62]. Additionally, the quality of a policy theory was posited, with assessable categories such as limitations, structure, and the means of evaluation [62]. These assumptions have led Hoogerwerf [62] to conclude that although there was an abundance of knowledge gained about the effects on policy "there has, however, been little research into the factors that determine the structure and the quality of policy theories. The determinates of the structure and the quality of policy theories may be found in:

(a) the political subculture

(b) the role of the person

(c) the nature of the political process

(d) the policy field; and

(e) the influence of new information" [62]

This statement, supra, and the previous assumptions about the phenomenon and quality of policy, make a vague intimation to the existence of policy intelligible grounding, and perceptible stratal moments, without coming to the full realisation of their conceptual existence, distinctions and relationship. This type of analytical vaguery is also found in literature regarding policy analysis [63]. Although perhaps strictly useful for existential cognition, public policy analysis was defined as "determining which of various alternative public or governmental policies will most achieve a given set of goals in light of the relations between the policies and goals" [63]. The implicit assertion made by this definition is that public policy analysis is disconnected from precognition, the endogenous ethos, and the phenomenal starting points of policy. The definition by Nagel [63] implicitly asserts that policy is an exogenous phenomenon, applied to existence as a means to reach a goal. It is interesting how Nagel's [63] definition is devoid of any reference to what is, but rather to only what could be: the policy goal. Even the intimation that there is a 'relation' between policies and goals is an implicit assertion that policy outcomes are not independent of policy concepts, and that 'relations' is an implication of causative separations between policies and goals which in effect are integral, constituent elements of the policy noumenon which are projected into the policy phenomenon. Some of the conceptual vagaries represented by literature surrounding policy theory and analysis were a consequence of the difficulties inherent in developing theories of public policy formation [64]. Indeed, “...public policy becomes troublesome as a research focus because of inherent complexity - specifically because of the temporal nature of the process..." [64]. As evidenced by the research, the temporal nature of the policy process is synchronic and diachronic in both actualisation and analysis. Importantly, Greenberg, et al [64] stated, “...improving our understanding of policy phenomena is clearly possible, if only through advancing the conceptual sophistication of theoretical formulations". There can be an advancement of conceptual sophistication inasmuch as "the collision between theory and data, while perhaps frustrating at first, can have important benefits for both researchers and theorists [64]. The reasoning from Greenberg, et al [64] is indicative of the temporal role of induction in theory formation. The policy analysis defined by Nagel [63] can be categorised as normative, in the sense that it focused on a goal, whereas the policy analysis as described by Greenberg, et al [64] can be categorised as positive, in the sense that it focused on what is existing in space and time.

\section{The Frameworks 'fit' and relation to pre-existing frameworks}

The frameworks are, at their essence, noetic with a noumenal projection into phenomenal experience and practical implementation. Perhaps most importantly for the understanding of the role, place and 'fit' of the frameworks is to distinguish them from existing, developed policy frameworks found in literature. The seminal article by Jenkin-Smith and Sabatier [61] identified the "textbook approach" (p. 175) also called "the Stages Heuristic" (p. 175) as the traditional policy framework model that has provided a long-term means for policy analysis. However, Jenkin-Smith and Sabatier [65] posited that the Stages Heuristic has outlived their usefulness because of apparent drawbacks. The frameworks identified in the research are not necessarily off-setting the existing and 
Table 1. Comparative view of policy frameworks.

\begin{tabular}{ll}
\hline \hline Policy Learning Frameworks & Description \\
\hline Synchronic and Diachronic Frameworks & Noetic / Cognitive \\
& Phenomenal \\
& Intrinsically relational (two frameworks) \\
& Policy 'moments' with intrinsic causality \\
& Policy change in the moment and long term \\
& Policy learning in the moment and long term \\
& Dynamic \\
& Holistic focus \\
& Aggregate unit of analysis is abstracted conception \\
\hline The Stages Heuristic Framework & Phenomenal \\
& Breaks policy process into standard sub-processes \\
& Lacks causality \\
& Lacks relational aspect between segments \\
& Focus on outcomes \\
& Top-down focus \\
& Limited to temporal unit of analysis \\
\hline Advocacy Coalition Framework & Phenomenal \\
& Policy change over long periods \\
& Policy learning over shorter periods \\
& Focus on policy sub-systems \\
& Causal conceptualisations of public policies \\
& Aggregate unit of analysis is holistic policy domain (actors) \\
\hline \hline Institutional / Rational Choice Framework & Phenomenal \\
& Focus on individual institutions \\
& Assumptive of rationality in policy decision-making \\
& A-posteriori analysis justification of policy process rather than a-priori \\
\hline Comparative Framework & Phenomenal \\
External in scope \\
Systematic approach by disaggregating external policy elements \\
Aggregate unit of analysis is pre-existing policy model \\
\hline
\end{tabular}

well utilised policy frameworks, but instead provide a new, alternative, and systematic approach. This is established a-priori because all of the pre-existing frameworks are fundamentally phenomenal, without accounting for noetic and causal moments in the process. Table 1. below provides a comparative view of the frameworks when compared to the basic qualities and tenets of pre-existing policy frameworks. The reference to the Stages Heuristic and the Advocacy Coalition Framework draws particularly from Jenkin-Smith and Sabatier [65]. Reference to the Institutional / Rational Choice Framework is attributed to Ostrom [66] and the Comparative Approach Framework is attributed to Schneider and Ingram [67].

The authors, Jenkin-Smith and Sabatier [65] seem to begin to conceptualise the noetic aspects of policy learning and change by suggesting that "the principle glue holding a coalition together is agreement over policy core beliefs" (p. 183). Again, the authors refer to an aspect of a noetic framework without quite defining it: “...the only way to change the policy core attributes of governmental policy is through some shock originating outside the subsystem..." (p. 183). This could be interpreted as a reference to the synchronic - diachronic relationship of a policy learning framework. The depth of conceptualisation is limited at the insufficiently abstracted phenomenal level and perhaps inadequate use of words to convey meaning. An assumption based on a reading of literature can be made, therefore, that the frameworks derived from the research data are not related to pre-existing framework concepts, but they do provide a more abstracted and holistic means for policy learning and causal analysis.

\section{CONCLUSION}

\section{A. Policy theory implications}

The finding of policy learning frameworks that were derived from indicators and themes in the data provides a means for a deeper understanding of actualisation and analysis of Russian liberalisation policy over time. The learning frameworks have implications for broader policy theory in the Russian context; Russian economic policy; and concepts of causation and change over time.

The frameworks hold internal and external validity inasmuch as they are derived and abstracted from intellectual and empirical data. The frameworks provide structure for international policy learning and discovery and have applicability in public and private sector policy actualisation and analysis.

The frameworks can be used to dissect and develop policy and associated theory 'over time', in the areas of policy intelligible grounding and quantification of the policy components. Policy theory is also further developed by the frameworks 'in the moment' in the sense that the clarity applied to the interface between existing policy and (re)actualisation of policy provides a means 
to reconceptualise an immutable first concept, based on measurable, empirical evidence.

The research findings support Littlechild's [13] general assertion that there are distinctions between countries, but the basic elements of liberalisation can apply to 'learning' entities with evolving, contextualised policy and implementation.

\section{B. Recommendations for future research}

With reference to Russian power sector liberalisation with infrastructural and policy tenet integration with external entities, the following four points are recommended for future research:

1. The degree and effects of internal 'coercive isomorphism' should be studied with the aim of examining the potential proportionate attenuation of policy evaluation and reflexive policy learning.

2. The effects of broad marketisation and institutional change over time on the implementation of microlevel power sector or networked industry liberalisation policy.

3. The dynamic relationship between adapting a metaliberalisation policy in the power sector while physically integrating the power system with other countries with distinct, mixed-market policy directions.

4. Counterfactual studies of the power sector: structural, operational, and investment alternatives to liberalisation policy.

With a broader, theoretical view built upon some of the empirical findings, the following two points are recommendations for new or extended theoretical research:

1. The constituent and unified concepts within the policy learning frameworks are all opportunities for further research. The frameworks themselves are 'theoretical' and are elements of noetic and phenomenal criteria and parameters of policy learning theory. However, starting points for further theory development can be found in the frameworks' conceptual and relational properties and their interface with reality.

2. The frameworks, as a matter of policy validity verification, should be utilised as a means of analysing on-going Russian power sector liberalisation and other, international policy learning processes. Because of the nature of policy learning and change, it is possible that, given a longer period of time and additional resources, the components of the frameworks can change, and relational properties reassessed, along with a redefinition of policy learning and learning moments over time.

Despite the fact that power sector liberalisation policy experiences such as Britain's were frequently touted as international models to be emulated, the Russian experience with liberalisation policy change and direction of change, inclusive of causation, motivation, policy creation, policy learning, and implementation, indicated that although valuable, prominent international models cannot be wholly, successfully transplanted without being integrated with the political, legal and industrial realities of the learning entity. This finding, and its policy learning theoretical underpinnings, led to an identification of internally and externally valid, intelligible policy learning frameworks for the analysis and actualisation of public policy.

\section{REFERENCES}

[1] L.S. Belyaev, Electricity Market Reforms, Economics and Policy Challenges. Springer: New York. 2011.

[2] S. Palamarchuk, and N. Voropai, "Status and Development of the Russian Electricity Market". IEEE General Meeting. Paper \#09GM1410. Alberta, Canada: 2009.

[3] S. Palamarchuk, and N. Voropai, "Russia's Power Industry restructuring: Current State and Problems". [unpublished] Irkutsk, Russia: Energy Systems Institute. 2003.

[4] B. Arnot, Controlling Soviet Labour: Experimental Change from Brezhnev to Gorbachev. New York: M.E. Sharpe, Inc. 1988.

[5] J. Surrey, ed. The British Electricity Experiment, Privatisation: The Record, the Issues, the Lessons. London: Earthscan Publications, Ltd. 1996.

[6] Organisation for Economic Co-Operation and Development (OECD) (2002a) OECD Economic Surveys 2001-2002 Russian Federation. Paris, France: OECD Publications.

[7] G. Aslanyan, et al., "Monitoring the Sustainability of Russia's Energy Development". Natural Resources Forum. Vol. 29. 2005.

[8] B. Black, and A. Tarassova, "Institutional Reform in Transition: A Case Study of Russia”. Working Paper No. 237. Stanford: Stanford Law School.

[9] R. W. Bacon, J. Besant - Jones, “Global Electric Power Reform, Privatisation and Liberalisation of the Electric Power Industry in Developing Countries". Energy and Mining Sector Board Discussion Paper Series: The World Bank Group. 2002.

[10] R. Pittman, "Restructuring the Russian Electricity Sector: Re-creating California?" Energy Policy. Vol. 35. pp. 1872-1883. 2007.

[11] R. Eising, "Policy Learning in Embedded Negotiations: Explaining EU Electricity Liberalisation." International Organisation. Vol. 56, pp. 85-120. 2002.

[12] L. H. Pederson, "Transfer and Transformation in Processes of Europeanisation." European Journal of Political Research. Vol. 45, pp. 985 - 1021. 2006.

[13] S. C. Littlechild, Privatisation, Competition and Regulation in the British Electricity Industry, with Implications for Developing Countries. Joint UNDP. World Bank Energy Sector Management Assistance Programme (ESMAP): Washington, D.C. p. 4. 2000.

[14] T. Hori, T. "Creating the Wholesale Market for Electricity in Japan: What should Japan Learn from Major Markets in the United States and Europe?" Centre for Energy and Environmental Policy Research: 
MIT. 2001

[15] S. C. Littlechild, Electricity: Regulatory Developments Around the World. London: IEA/LBS. 2001.

[16] N. I. Voropai, and Y. N. Kucherov, "Russia and the EU Electricity Directive." IEEE Power Engineering Review. (4). 2000.

[17] Energy Charter Secretariat(ECS). Conclusions Adopted by the Energy Charter Conference on 10th December 2003 with Respect to the Energy Charter Country Reports on Investment Climate and Market Structures in the Energy Sectors of the Russian Federation and the Slovak Republic. Brussels, Belgium: ECT. 2003.

[18] Europa, 2004a. Energy Charter. [online]. Europa European Commission - Energy. Available from: http://europa.eu.int/scadplus/leg/en/lvb/127027.htm [Accessed 1 Jan. 2004] p. 2.

[19] R. Green, "Markets for Electricity in Europe." Oxford Review of Economic Policy. Vol. 17 (3). 2001.

[20] CIS Electric Power Council. Current Status and Development of CIS Countries' Power Sectors. Submitted for the Energy Charter Seminar "Liberalizing Trade and Investment in the Eurasian Power Sector", 3 October 2002, Brussels. 2002.

[21] Asia-Pacific Economic Cooperation (APEC). Electricity Reform in APEC Economies - The Way Ahead. Peter Smiles and Associates, Resource Law International, APEC Energy Working Group. 2003.

[22] K. Vlahos, et al. "An Integrative Modelling Approach for Understanding Competitive Electricity Markets." The Journal of the Operational Research Society. Vol. 49. (3). 1998.

[23] M. E. Beesley, Privatisation, Regulation and Deregulation. London: Routledge. 1997.

[24] Organisation for Economic Co-Operation and Development (OECD). Regulatory Reform in Gas and Electricity and the Professions. OECD Publications, Paris, France. 2002.

[25] S. C. Littlechild, "Competition and Regulation in the U.K. Electricity Industry (With a Brief Look at California)." Journal of Applied Corporate Finance. Vol. 13. (4). 2001.

[26] D. Newbery, Regulating Electricity to Ensure Efficient Competition. Cambridge: Department of Applied Economics. 2001.

[27] F. P. Sioshansi, "Sobering Realities of Liberalizing Electricity Markets." International Association for Energy Economics Newsletter. Third Quarter. 2002.

[28] X. Yi-Chong, "The Myth of the Single Solution: Electricity Reforms and the World Bank." Energy. Vol. 31, pp. 802-814. 2006.

[29] International Energy Agency (IEA) Russian Electricity Reform, Emerging Challenges and Opportunities. Paris, France: OECD. 2005.

[30] N. Ivashchenko, and L. Savchenko, "Restructuring the Russian Economy: Problems and Tendencies." Centre for Economic Reform and Transformation, Dept. of Economics, Heriot-Watt University, Edinburgh.
[31] A. Belyi, et al. "Challenges to Russia's Post-RAO UES Energy Paradigm: a Window of Opportunity for Sustainable Market Development." Journal of World Energy Law and Business. Vol. 4. (2). 2011.

[32] O. Oksanen, et al., "Electricity Markets in Russia, the US and Europe." Proceeding from: 2009 6th International Conference on the European Energy Market EEM 2009.

[33] V. Maslennikov, Professor Victor Maslennikov, Director of the 'Extreme Temperatures' Institute of the Russian Academy of Sciences in Moscow. Email interview. 2010.

[34] A. Abalmasov, and D. Kolodin, "Market Power and Power Markets: Structural Problems of [the]

Russian Wholesale Electricity Market." Economics Education and Research Consortium. Russia and CIS. 2002.

[35] S. Kurronen, Russian Electricity Sector - Reform and Prospects. Bank of Finland, BOFIT: Institute for Economies in Transition. 2006.

[36] K. Eisenhardt, "Building Theories from Case Study Research." Academy of Management. The Academy of Management Review; 14, (4). 1989.

[37] J. Gerring, J. Case Study Research, Principles and Practices. Cambridge: Cambridge University Press. 2007.

[38] M. A. Lamoureux, "Economic Convergence Points of Russian, CIS and Asian Power Markets." Montreal: Paper published at the Power Engineering Society General Meeting, IEEE. 2006.

[39] C. Marshall, and G. Rossman, Designing qualitative research, Thousand Oaks: Sage. 1999.

[40] M. Miles, and A. Huberman, Qualitative Data Analysis: an expanded sourcebook, Thousand Oaks: Sage. 1994.

[41] K. Punch, Introduction to Social Research Quantitative and Qualitative Approaches, London: Sage. 1998.

[42] J. Mason, Qualitative Researching, London: Sage. 2002.

[43] R. A. W. and D Marsh, "New Directions in the Study of Policy Networks." European Journal of Political Research, 21: 181-205. 1992.

[44] A. Onwuegbuzie, and K. Collins, "Typology of Mixed Methods Sampling Designs in Social Science Research." The Qualitative Report, Vol. 12 (2), June, 2007.

[45] M. Q. Patton, Qualitative research and evaluation methods (2nd ed.). Newbury Park, CA: Sage.

[46] L. Carlsson, "Policy Networks as Collective Action." Policy Studies Journal. Vol. 28, (3). 2000.

[47] K. Hanf, and F. W. Scharpf, (Eds). Interorganisational Policymaking. London: Sage Modern Political Studies. 1978.

[48] P. Kenis, and V. Schneider, Policy network and policy analysis: Scrutinizing a new analytical toolbox. In B. Marin, and R. Mayntz (as.), Policy networks, empirical evidence and theoretical considerations (pp. 25-59). Frankfurt am Main: Campus Verlag. 1991. 
[49] G. Jordan, "Sub-governments, Policy Communities and Networks: Refilling Old Bottles?" Journal of Theoretical Politics, 2 (3). 1990.

[50] D. Marsh, and M. Smith, "Understanding Policy Networks: Towards a Dialectical Approach." Political Studies Association. Vol. 48, pp. 4 -21. 2000.

[51] M. Gall, et al. Educational research: an introduction, White Plains: Longman. 1996.

[52] J. Morse, "The Significance of Saturation (Editorial)." Qualitative Health Research. Vol. 5. P. 147. 1995.

[53] M. Evans, and J. Davies, "Understanding Policy Transfer: A Multi-level, Multi-disciplinary Perspective." Public Administration. Vol. 77 (2), pp. 361 - 385. 1999.

[54] M. M. Crossan, et al. "An Organisational Learning Framework: From Intuition to Institution." The Academy of Management Review. Vol. 24. (3), pp. 522537. 1999.

[55] P. May, "Policy Learning and Failure." Political Science. Vol. 12 (4) pp. 331-354. 1992.

[56] O. James, and M. Lodge, "The Limitations of 'Policy Transfer' and 'Lesson Drawing' for Public Policy Research." Political Studies Review. Vol. 1., Pp. 179193. 2003.

[57] C. Meseguer, "Policy Learning, Policy Diffusion, and the Making of a New Order." The Annals of the American Academy of Political and Social Science. Vol. 597. Pp. 67-81. 2005.

[58] C. Schlager, "A Comparison of Frameworks, Theories and Models of Policy Processes", in: Sabatier, P. Theories of the Policy Process. University of California, Davis: Westview Press. 2007.

[59] T. James, and P. Jorgensen, "Policy Knowledge, Policy Formulation, and Change: Revisiting a Foundational Question.” The Policy Studies Journal. 37, (1), p. 141162. 2009.

[60] H. D. Lasswell, "The emerging conception of the policy sciences." Policy Sciences, 1 (1) pp. 3-14. 1970.

[61] P. A. Sabatier, (Ed), Theories of the Policy Process. Cambridge, MA: Westview Press. 2007.

[62] A. Hoogerwerf, "Reconstructing Policy Theory." Evaluation and Program Planning. Vol. 13, pp. 285, 290. 1990.

[63] S. Nagel, "Conceptual Theory and Policy Evaluation." Public Administration \& Management. Vol. 6 (3). 2001.

[64] G. D. Greenberg, et al. "Developing Public Policy Theory: Perspectives from Empirical Research." The American Political Science Review. Vol. 71. (4), p. 1532, 1543. 1977.

[65] H. Jenkins-Smith, and P. Sabatier, "Evaluating the Advocacy Coalition Framework." Journal of Public Policy. Vol. 14, (2). 1994.

[66] E. Ostrom, "Rational Choice Theory and Institutional Analysis: Toward Complementarity." American Political Science Review. Vol. 85. (1). 1991.
[67] A. Schneider, and H. Ingram, "Systematically Pinching Ideas: A Comparative Approach to Policy Design." Journal of Public Policy. Vol. 7. (1). 1988.

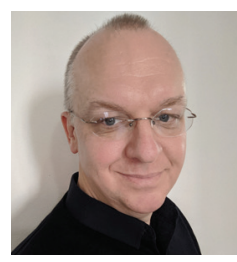

Marcel Lamoureux is a political scientist and social theorist. He holds a Ph.D. in political science from Glasgow Caledonian University, Glasgow, Scotland, UK; an M.A. in continental philosophy from Staffordshire University, Stoke-on-Trent, UK; an M.A. in management from Norwich University, Northfield, Vermont, USA; and a B.A. in philosophy from Wadhams Hall College, Ogdensburg, New York, USA. Dr. Lamoureux has over 30 years of experience in the electric utility industry, and academia. He resides in Florida, USA. 